June 1931 a further cylinder followed. These three cylinders have now been exposed for periods of 14 years, $10 \frac{1}{2}$ years and $7 \frac{1}{2}$ years respectively. The first is covered with a dark brown film, the second with a straw-coloured film, whilst the third as yet shows only a slight dulling of the surface. This evidently slower rate of film thickening, in the case of the third cylinder, may be due to its having a mirror finish as compared with a fino emery finish in the case of the other two cylinders.

The solutions wero examined in August 1938, and from these figures the weight of iron and of chromium dissolved from the cylinders was calculated, and it was found that there was a deficiency of chromium in relation to the iron when the relative proportions in which these two elements were present in the steel were taken into account. It was then assumed that this missing chromium is present in the form of $\mathrm{Cr}_{2} \mathrm{O}_{3}$ in the films on the surfaces of the cylinders, and the amounts were calculated.

It is interesting to note that the calculated thicknesses of the films on the first two cylinders are not far removed from the value of about $4 \times 10^{-8}$ which is obtained from the work of several investigators for the thickness of films giving a similar coloration. In the case of the third cylinder, the calculated film thickness is less than the minimum thickness required to give a definite coloration.

It was quite accidentally discovered that a oylinder of 13 per cent chromium steel which is apparently not affected by nitric acid but is soluble in sulphuric acid, became passive for long periods in sulphuric acid after immersion for a period in nitric acid. This observation was made some fifteen years ago and before we had obtained the interesting data from the three cylinders of 18/8 material. Evidenco indicates that the corrosion-resisting properties of the rustless steels are due to the chromium facilitating the spontaneous production of a protecting film of the necessary characteristics for resistance, which film if damaged is spontaneously renewed.

Experimenting upon the basis of the rustless steel compositions, it has been found that by modifying the chromium and nickel and also by adding other elements such as tungsten, molyb. denum, cobalt or titanium, steels are produced which maintain a reasonably protective film at temperatures even in excess of $1000^{\circ} \mathrm{C}$., and also have useful strength.

\title{
THE ROYAL AGRICULTURAL SHOW
}

\section{By Prof W. B. Brierley}

$\mathrm{I}^{\mathrm{N}}$ English agriculture the "Royal Show" is the peak of the year, and the occasion in 1939 is of special significance as it marks the centenary of the Royal Agricultural Society of England. It is fitting, therefore, that the Show should be held during July 4-8 in the Royal Park of Windsor, and that the University of Reading, which increasingly plays a leading part in agricultural education and research, should have been invited to accept responsibility for the scientific exhibit. The exhibition in the building devoted to education, research and marketing was arranged by the Faculty of Agriculture and Horticulture of the University (including the National Institute for Research in Dairying and the British Dairy Institute) with additional exhibits by the counties of Buckingham (acting in co-operation with the Buckinghamshire Producers) and Northampton.

For many years, the scientific exhibit at the Royal Show has been of very high calibre, and this is all the more creditable when it is remem. bered that agricultural teaching does not lend itself to exhibition, and that agricultural research is of a somewhat plodding nature and that it possesses none of the more spectacular qualities of research in many other branches of science. Each year, however, it has become increasingly difficult to improve on the interest of former exhibits or to vary them in kind, and for the special occasion of a centenary show the young University of Reading was faced with an exceptionally difficult task. It achieved a notable success due, primarily, to two facts: first, the entire exhibit was arranged on the central theme of the progress in agricultural research and its application to practice during the last hundred years, and, secondly, the individual exhibits were merged in a common decorative scheme designed and produced by the School of Art of the University of Reading. The many scientific exhibits were excellent, but it was the happy marriage of science with art which remains the outstanding impression left by the scientific building.

In any scientific exhibition the benches are occupied by specimens, instruments, etc., but it is always difficult to know what to do with the wall 
space. Sometimes it is just left as a blank and rather depressing area; more usually it is filled with graphs, tabular or textual matter which fow people look at and which frightens many people away. It is, however, in the efficient and attractive use of wall space that the artist can render such valuable aid and, in the Royal Show exhibit, probably more people looked at the walls than at the benches. The scientist gave specific information, but the artist gave the general mental impression which synthesized the data, and which remained when specific facts were forgotten.

All interested know of the serious reduction in the total cultivated area of Great Britain, the reversion of the relative importance of arable and grass, the fall in the cereal acreage, especially wheat, the partial replacement of the old root break and the appearance of the new sugar beet crop, and the increase in the acreage under potatoes and fruit, but few things could do more to bring home to the general public the reality of these changed conditions than the economics exhibit, with its pictorial representations in the form of large colourful wall panels occupying the centre of the building. Similarly, a number of smaller but very attractive panels depicted corresponding changes in the numbers of dairy cows, poultry and pigs, and the decrease in the numbers of horses and sheep. A further panel portrayed one of the most lamentable facts of British farming, the exodus from the land.

With the National Institute of Research in Dairying and the British Dairy Institute contributing to the exhibition, it was only natural that milk and milk products should occupy a prominent place. Their joint exhibit was designed to present a picture of the progress of dairying and dairy science during the last hundred years, and its success was very evident. Two flanking panels, "1839" and "1939", showed in vivid contrast the change in the organization of the dairy industry during this period, and a central panel indicated landmarks in dairying; one very important landmark being the foundation of the National Institute itself so recently as 1912. Other panels illustrated progress in more specific aspects of research, such as the better breeding and feeding of dairy cattle, vitamins in milk, and the value of clean milk as food.

Cattle have always been recognized as important livestock but, during recent years, the despised pig has also acquired merit and its numbers have correspondingly increased. In pig breeding a basic factor is accurate recording, and the importance of this was well illustrated in a special exhibit.

Also, during recent years, the poultry industry, once the Cinderella of agriculture, has developed so rapidly that it now stands third in economic importance. An excellent exhibit, backed by most attractive wall panels, showed this progress and demonstrated some of the changes in poultry husbandry and marketing which made it possible.

But farm animals like human beings are heirs to many maladies, and the veterinary scientist plays the same important part in agriculture that the medical man plays in human society. During the last hundred years notable progress has been made in this field, and this was portrayed in an interesting exhibit in which particular attention was given to tuberculosis, parasitic gastro-enteritis and contagious abortion.

An important line of research carried out at Reading is soil surveying, a science of pedology only some fifteen years old. This work was illustrated by some beautifully coloured maps and by the profiles of twelve different soils occurring in Berkshire and Hampshire. Somewhat related to this was an exhibit illustrating the Land Fertility Scheme. The Government's scheme came into operation in September 1937, and the work carried out under it has already given valuable insight into fertility problems as a whole and certain special problems in particular.

In all agricultural matters and problems we return inevitably to the soil. As St. Francis sang, "Praised be, my Lord, for our sister, Mother Earth, which doth sustain and keep us, and bringeth forth divers fruits, and flowers of many colours, and grass". But the soil is not just dead matter, a physico-chemical system for pedologists and chemists to dissect. It is a vast unexplored realm of living things, a land of Lilliput with teeming populations of microscopic plants and animals, eating, breathing, reproducing their kind, and fighting for existence in a struggle as relentless as any in our Brobdingnagian world. The most important of these soil microbes are the bacteria and fungi for, ultimately, all life and all living things are dependent upon them for existence. In two interesting exhibits, backed by decorative and informative wall panels, the story of these soil microbes was well told.

It would be almost impossible to construct any scientific exhibition relating to agriculture in which pointed attention was not given to the vital necessity of grassland improvement. Progress in this field was well illustrated by an exhibit "Two blades of grass where one alone was seen before", which showed clearly the improvement in the management of grassland due to the use of the best herbage plants and pedigree strains, aided by controlled cultivation, manuring and grazing.

A complete representation of a century's progress in arable crops would have been extremely interesting, but the difficulty of shorring improvement in roots rendered such an exhibit practically 
impossible. There was, however, a valuable and finely staged exhibit showing improvement in cereals, which included mature growing plants, of varieties of wheat, oats and barley that were grown approximately a hundred years ago and an equal number of well-known modern rarieties.

With the increasing recognition of the value of protective foods, horticultural crops in many ways now rival agricultural crops in importance, and the value of scientific research in horticulture is rapidly attracting attention. Under modern competitive conditions high quality produce only is demanded, and this is unobtainable from neglected and pest-ridden orchards and gardens. This was exemplified partly in an exhibit designed to stress the differences between the old-fashioned ill-kept orchard and the modern plantation run on commercial and scientific lines, and partly in an exhibit of vegetables, salads and fruits grown in the intensively farmed area of Buckinghamshire.

Finally must be mentioned the garden in front of the scientific building, which was laid out by the University Department of Horticulture to a design prepared by the Department of Landscape Architecture. A magnificent centre bed displayed the carpet bedding fashion of a century ago, whilst two flanking beds showed a modernistic treatment.

The entire exhibition was a notable success, informative and stimulating in its portrayal of the interest of agricultural and horticultural research and of its value in practice, and not only colourful but also satisfyingly beautiful in the artistry of its design and production. The exhibit was worthy of the Royal Centenary Show and set a standard which it will not be easy to maintain.

\section{OBITUARIES}

\section{Dr. W. M. Childs}

$\mathrm{D}$ R. W. M.:CHILDS, principal of University College during 1903-1926 and first vice-chancellor of the University of Reading during 1926-1929, died at his residence, Grimsbury Bank, Hermitage, Berkshire, on June 21, aged seventy years.

In the history of the modern English universities, no one has played a part corresponding at all closely to that of William Macbride Childs. With the exception of Reading, the universities which have arisen during the past fifty years have developed from earlier colleges, with an established tradition of teaching and research as the justification for their academic independence. But the whole history of the movement which created the University of Reading is comprised within a period of less than half a century. The institution to which Childs went as a lecturer in 1893 was little more than a centre at which work initiated by university extension classes could be carried to a further stage; it had scarcely the rudiments of an academic organization, and its financial resources were meagre and uncertain. It is the supreme distinction of Dr. Childs that he saw the possibilities latent in this small and anomalous institution, devoted his life to their realization, and impressed the stamp of his personality on the college and university which came into being through his efforts.

Childs was enabled to succeed in what seemed at first a hopeless task by the intensity of his belief in his ideals, and by his power of imparting his own convictions to others who could help him. He possessed the rare faculty of constructive imagination. To him, the ideal university was a community of teachers and students, informed by a lifo and spirit which transcended the achievements of individuals. From the pursuit of this ideal he never turned aside. But unlike many idealists, he had the habit of mind which finds pleasure in practical details, and his patience could never be exhausted. He planned every stage in the long process through which the eollege at Reading came to university independence. The addition of one department after another to the nucleus of a college with which his work began, the creation of an academic organization, the establishment of halls of residence for students, were all, to him, matters of intense personal interest. For thirty years he concentrated the abilities of one who was by nature a man of affairs upon the details which gave form and substance to an ideal.

In course of time, the influence of Childs' personality and work spread beyond the circle of his immediate associates. It was his devotion to his chosen task, and the transparent sincerity of his conviction that the creation of a university in Reading was a work which any man might bo proud to advance, which brought to the college the endowments essential to its growth. On the general history of the modern universities, his influence, though indirect, was real. The most original part of his work at Reading was the establishment of a system by which all students not drawn from the immediate neighbourhood live in halls of residence. To-day, the value of life in a collegiate environment for students of a modern university is recognized everywhere. But when Childs conceived the idea of basing the University of Reading upon a residential system, little had been done in this direction elsewhere, and the opening of Wantago Hall in 1908 was the first effective demonstration of the fact that life under conditions similar to those which have prevailed for centuries at Oxford and Cambridge was possible for students of 